\title{
El juego en la infancia
}

\author{
Autor: MANUEL ZORRILLA ${ }^{1}$ \\ Comentario: NELSON A. VARGAS C. ${ }^{2}$ \\ 1. Médico de la Casa Nacional del Niño. \\ 2. Facultad de Medicina. Universidad de Chile.
}

\section{Introducción}

Por la época en que escribió y publicó este artículo (1933), el doctor Zorrilla era médico de la Casa Nacional del Niño, ex Casa de Huérfanos, ex Casa de Expósitos, donde hizo parte prolongada e importante de su carrera profesional.

La profundidad del análisis de Zorrilla prueba su característica de "hombre del mundo". En sus comentarios incursiona en las áreas filosófica, biológica y psicológica y muestra lo bien que invirtió sus recursos en Chile, al decidir impulsar el crecimiento de la universidad. Esto dio origen a una clase culta, motor y energía del progreso nacional. Zorrilla era miembro de esa clase, salida de una universidad, tal vez más completa en lo integral y menos tendiente a profesionalizar que la actual.

Es curioso y lamentable que hayan pasado décadas antes que la Pediatría nacional publicara un segundo artículo sobre un tema tan trascendente como es uno de los "trabajos" de los niños: jugar. Zorrilla fue pionero, no secundado por largo tiempo, en el tema de los juguetes y el juego.

Esta falencia hace pensar que es posible que la especialidad haya descuidado excesivamente a la puericultura, elemento vital en la promoción de la salud y la prevención de las enfermedades infantiles. En una larga lista de ignorancias nuestras, y por mencionar sólo al- gunas, en esos tiempos no se conocían el Kawasaki, el Parvovirus, el VIH, ni los antibióticos. Resulta razonable suponer que en los programas de estudio y en los currículos, en general, había espacio para preocuparse del cuidado de los niños sanos sin concentrarse -como temo que ocurre ahora- en los enfermos (la necesidad tiene cara de hereje y lo urgente no deja tiempo para lo importante).

\section{El juego en la infancia}

\section{MANUEL ZORRILLA}

Tema de verdadero interés, tanto desde el punto de vista psicológico como biológico puro, es el que se relaciona con el juego infantil, o, como se denomina en psicología, actividad lúdica. No lo pueden negar los pediatras, sobre todo, los que trabajan en asilos. Aquí es donde se llega a intimar profundamente con el niño, debido al largo período de vida, muchas veces la infancia entera, que permanece a nuestro lado. Y anotamos como un progreso evidente en el desarrollo, el que comience a jugar; como asimismo, estimamos de buen augurio cuando un niño postrado por una larga enfermedad, intenta de nuevo jugar.

Trataremos, en las líneas que siguen, de aclarar la significación del juego, teniendo como punto de vista principalmente, la novedosa teoría de Causí, un sabio Catalán. 
Hasta los comienzos de este siglo, la casi totalidad de las teorías que pretendían explicar el juego en los niños eran de carácter psicológico puro, y el problema era del resorte exclusivo de los filósofos. A medida que la biología adquiría preponderancia e iba invadiendo terrenos que antes no le pertenecían -como son los de la Pedagogía, la psicología misma, al hacerse experimental- se ven aparecer concepciones tenidas de cierto carácter biológico, hasta llegar al concepto biológico puro, cual es el del maestro Catalán que antes mencionamos.

Antes de entrar a enumerar las más importantes teorías que han antecedido a la de Causí, trataremos de aclarar que entendemos por juego, ateniéndonos a las modernas concepciones. Seria la actividad espontánea por excelencia del niño; actividad física a la que va unida también actividad psíquica. Así planteado el asunto, la actividad del lactante pequeño, menor de 6 meses expresada en movimientos desordenados de todo orden, no seria juego, ya que la actividad psíquica o inteligencia, en esta época es nula. Esta etapa del lactante en que prima el automatismo, podría considerarse como preparatoria o de pre-ejercicio. Seria una época en que perfeccionaría las funciones orgánicas que más tarde utilizara, (dinámicas, estáticas, sensoriales, etc). El juego propiamente tal, comenzaría a aparecer cuando la actividad automática se diluye para dar paso a la actividad instintiva ( $5^{\circ}$ a $\left.6^{\circ} \mathrm{mes}\right)$. La actividad lúdica se traduciría entonces por aquellas expresiones infantiles que no tienen realmente equivalencia en la mentalidad adulta. Sería lo que vulgarmente se llama retozar, chacotear. Y quedaría fuera de esta orbita mucho de lo que comúnmente se entiende por juego: Ej. el juego a los soldados, muñecas, visitas, que serían producto de imitación; los deportes, como el fútbol, box, etc, que se entenderían como actividades musculares sistematizadas y codificadas por los adultos; y aún muchos juegos que siendo netamente infantiles en su génesis, han sido perfeccionados, es decir, desfigurados también por los adultos (volantín, trompo, etc). Existe, como se ve, toda una escala de juegos que van desde el juego propiamente tal, generado y ejecutado exclusivamente por el niño, hasta el producto de imitación, pasando por aquellos juegos, creaciones de adultos, en que se ha pretendido interpretar el sentimiento infantil.

Entre las más importantes concepciones en orden cronológico, comenzaremos por citar la teoría de Locke. Este filósofo formuló que el niño jugaba respondiendo a la necesidad de recrearse, de reintegrar fuerzas perdidas. Sería algo comparable al alimento o al sueño. Partió del concepto vulgar del adulto, que juega por descansar. Este criterio asiste aún a muchos maestros cuando largan a sus alumnos a recreo, después del estudio. En otro terreno, sería, como la jugada al cacho después de la salida de la oficina. En el niño, sucede lo contrario, juega más, mientras más descansado está. El cansancio inhibe la actividad lúdica.

Otra teoría vulgar, aceptada por una serie de filósofos, formulada primeramente por Beneke y perfeccionada por H. Spencer, es aquella de que el niño juega para librar a su organismo de un exceso de energía. Entre otros argumentos, aducen el que el niño posee un grueso panículo adiposo, significando acúmulo de energía. Spencer agregó que este excedente de energía era gastado en la imitación de actividades serias y útiles, hecha en forma desinteresada (actividad seria y útil, pero interesada, seria el trabajo, el otro polo del juego). Pero todo médico sabe que en la infancia priman los procesos de asimilación, que es esta una época de formación y almacenamiento. Ridículo sería pensar que un organismo en perpetuo acrecentar tenga energías de sobra para dilapidarlas en el juego.

Respecto a la imitación, desde luego, el niño cuando nos parece que imita, es que lo hace muy en serio, y cree en lo que representa. Sólo muy pocos juegos arrancan de una imitación. Ahora, respecto a lo de la utilidad, el niño no sólo imita lo útil, sino que más comúnmente lo inútil o perjudicial (juego en los niños vagabundos, proletarios).

Ha tenido cierta boga la teoría biogenética. Así como se ha creído que la evolución material del individuo, resume la evolución de las especies que le precedieron; se ha creído que en la evolución psíquica del hombre; desde que nace hasta la madurez, se van reproduciendo las etapas porque ha pasado el desarrollo de la humanidad. Y tendríamos, como dos paralelas, 
de un lado: el lactante de predominio automático; el niño, instintivo; el adulto, con voluntad y conciencia, y de otro: los pueblos que han ido pasando del salvajismo a la barbarie para llegar a la etapa de civilización. Los juegos serían entonces reminiscencias de actividades ancestrales hoy inútiles. Hoy día no se acepta esta manera simplista de relacionar la fotogenia con la ontogenia.

Como primera teoría, con un gran contenido biológico y de gran aceptación aun, hoy tanto entre biólogos como educadores aparece la teoría de Groos (de Tubingen) que en resumen interpreta el juego como una preparación a la vida seria del adulto por medio del perfeccionamiento de los instintos. Según vaya a ser esta actividad seria del adulto, así será la fisonomía del juego. Expone múltiples ejemplos: el cabrito que se entretiene dándose de cabezazos; el gatito, persiguiendo una pelota, cosa que dejará indiferente al cabrito: los perros nuevos que juegan mordisqueándose; la niñita, a las muñecas, en tanto que el niño preferirá siempre los soldados, etc.

Mientras más complicada es la actividad psíquica del animal, es decir, mientras más se eleva en la escala zoológica, más complicados serán sus juegos preparatorios. Los múltiples instintos, borrosos en el niño, se van perfeccionando con el juego. Groos clasifica los juegos según los instintos a que irían ligados. Así, v. gr.; el juego de muñecas, al instinto sexual; el juego a las visitas, al instinto gregario o social; juegos agresivos, al instinto de conservación, etc.

Analizando Causí esta teoría del sabio alemán, estima que de ella se desprende que el juego en la infancia sería un accidente sin valor propio en la vida del hombre, ya que sería una época preparatoria a la madurez. Tal razonamiento sería tan lógico como decir que la madurez es una etapa preparatoria de la senectud. A lo sumo, podría decirse que la infancia es una época de transición a la madurez, y que ésta lo es de la vejez; pero no se puede decir que una época es preparatoria de otra. Además, la mayoría de los juegos que analiza Groos, y otros que olvida, no responden a ningún instinto. ¿Qué instinto cultiva el niño jugando a la pelota? Además, es de una exageración evidente eso de estar viendo en los juegos infantiles, gérmenes de actividades posteriores (fabriles, industriales, científicas, artísticas, etc). ¿Que actividades posteriores esboza el niño jugando al volantín, a las bolitas, al trompo, etc?. Si juega a las visitas, al paco-ladrón, al almacenero, a las muñecas, es porque imita las actividades que ve a su alrededor. Vemos corrientemente en los campos al niño jugar haciendo de jinete en una varilla: arreando bueyes imaginarios, etc. Aquí, en la Casa Nacional del Nino, donde el niño tiene muy poco que imitar, hemos encontrado niños que se entretenían examinando la garganta de un compañero con un palo o una cuchara, sin que esto quiera significar, seguramente, que esos niños tengan inclinaciones médicas.

Por otra parte, hay animales de instintos muy complejos como son las abejas, hormigas, algunas aves, etc, que no tienen antecedentes de juego.

Otra consideración: Según la teoría de Groos el niño pasaría a ser un hombre en pequeño, ya que en último término trata de hacer lo mismo que el adulto en menor escala. Las conclusiones pedagógicas son desastrosas, por cuanto no habría sino que trasladar la actividad definitiva del adulto al niño para abreviar este aprendizaje que significa el afinamiento de los instintos. Esto sería, dice Causí, como si se pretendiera hacer coincidir el mediodía con la aurora, dando vueltas hacia atrás las agujas de un reloj. Llega aún a creer que el niño no juega a lo que va a ser, sino que el hombre es, lo que el juego dejó impreso en su mente infantil; es decir, en vez de condicionar la vida adulta al niño; sería este el que condicionaría al hombre.

Carr es autor de una teoría que tiene cierta importancia por ser también de carácter biológico. Dice que el juego es un estímulo del crecimiento orgánico. Pero aquí también se da el caso de que muchos juegos no entrañan ningún estímulo orgánico, como ser; el juego de muñecas. En este, se podría invocar la teoría de los instintos. Resultado: habría que elucubrar tantas teorías como juegos hay.

Antes de terminar esta enunciación de teorías, mencionaremos una de carácter psicológico, que aun tiene muchos adeptos. Es la que estima que los juegos liberan a los individuos de 
tendencias antisociales perjudiciales a nuestra civilización, Ej: juegos musculares deportivos. Pero, no hay que olvidar que estas tendencias sociales o antisociales, son creaciones de nuestro espíritu, son como se las ha llamado, relatividades históricas. Lo que hoy es antisocial, ayer no lo fue, y mañana será de otro modo. Nada hay más variable que el orden social para relacionarlo con algo inmutable, como es el juego infantil. El orden social cambiara constantemente en manos del hombre; el niño jugara siempre más o menos en igual forma. Por otra parte, hay pueblos salvajes donde las prácticas que pretendería desviar el juego son perfectamente admisibles. Y de otro lado, hay tendencias anti-sociales, como el robo, que la naturaleza no desvía con ningún juego. El niño no nace bueno ni malo. Somos los adultos los que lo juzgamos según nuestros puntos de vista. De ahí que no tenga tendencias perjudiciales de que desprenderse.

La actividad del individuo en cualquiera época de su vida es el resultado de un complejo de transformaciones químicas de naturaleza hormonal que influyen sobre los diferentes órganos o sistemas (nervioso, óseo, etc). Los estímulos y reacciones van variando con la edad, lo que ha resumido Marañon, diciendo que el timo es una glándula de infancia; la hipófisis, de juventud; los genitales, de madurez; el tiroides, de toda la vida.

El organismo infantil; tiene en general las mismas actividades que el adulto; pero sus expresiones son diferentes; porque se trata de un organismo en formación. La función eje y propia del niño en la escala somática es el crecimiento, y en la esfera psíquica, el fenómeno más resaltante es el juego. Es lógico que haya relación entre ambas actividades; crecimiento y juego.

Ahora, como el organismo del niño, dadas sus condiciones especiales de estructura, no puede producir otra actividad expresional que el juego, este pasa a ser el ejercicio específico de los organismos en formación. Cosa diferente es decir que el juego es un estímulo del crecimiento o el esbozarse de los instintos que más tarde constituirán la personalidad humana.

El juego aparece en la escala zoológica con la complicación de los organismos. Si son de escasa complejidad, comparativamente a los superiores, a pesar de poseer instintos, no tienen en su primer período actividad, lúdica (ej.: insectos, moluscos, aves, etc). Con la complicación de las estructuras aparece la vida psíquica superior hasta hacerse inteligencia en los mamíferos.

Recapitulando estas consideraciones, y para deducir que el juego no tiene relación con ninguna otra época de la vida fuera de la infantil, podemos anotar estas premisas:

1. Complejidad creciente física y psíquica de los organismos a medida que se asciende en la escala zoológica.

2. Siguiendo este orden, aparición de una infancia cada vez más larga.

3. Desemejanza, aunque equivalencia, entre las funciones del niño y del adulto, relacionadas con el substrato anátomo-fisiológico diversa. El organismo en formación tiene controles (hormonas) diferentes que el ya formado.

En el caso del gatito que corre tras la pelota de papel, no se trata de que se perfeccione para la caza. El instinto cazador esta preformado en su estructura orgánica. Responde a una constitución determinada. La imagen de las cosas que se mueven estimula su actividad que se traduce en movimientos de persecución. Pero independiente de los estímulos que obran sobre la motilidad, el gato, en su infancia desarrolla los músculos, adoptando actitudes y movimientos semejantes, sin otro estímulo que el que brota de sus reacciones internas. Es natural que entre lo que hace el gato joven y el adulto, haya semejanzas; pero semejanza no es dependencia.

Las distintas edades de la vida, son procesos de diferente significación vital que tienen comunidad de origen y que se entrelazan sin transiciones que interrumpan la continuidad del ser. Para que no hubiera semejanza sería necesario que con la edad cambiara la naturaleza del organismo. Ese origen invariable, hereditario, propio de la especie, influido, claro está, por el ambiente, es el que hace surgir siempre actividades idénticas, variables, en grado y energía, según las posibilidades de la materia viva.

Los cabezazos y saltos del cabrito no significan aprendizaje; son las manifestaciones de sus 
reacciones motoras que se desarrollan en la estructura muscular de sus miembros y sistema nervioso. Esta actividad motora, tiene, pues, un fin en sí misma.

Mientras mayor es la diferenciación orgánica, más complejo es el sistema nervioso y de mayor riqueza la vida psíquica. La escasa actividad lúdica de los animales inferiores esta en relación con la sencillez de la estructura nerviosa y su metabolismo.

El pollo no aprende a ser gallo o gallina; lo será desde el día que nace, con las limitaciones que le impone la potencia de sus órganos. Así, el pollo no mostrará ninguna tendencia a incubar, ni el gato, a la procreación, por la sencilla razón de que el estímulo adecuado a los órganos sexuales no ha alcanzado aun su madurez.

El movimiento es la materia prima del juego. El adulto posee el completo dominio de los movimientos y la capacidad de servirse de ellos como de instrumentos. En la infancia, con el desarrollo progresivo de los órganos, van apareciendo poco a poco movimientos nuevos que expresan la amplitud vital que adquiere poco a poco el organismo. Cada juego aparece en la época que el desarrollo psico-orgánico lo permite. Ahora, tomando en cuenta el factor intelecto tiene que haber diferencia entre el juego del hombre y el de los animales. En los últimos, aquellos órganos que durante la vida desempeñan una función útil a el o a la especie, se expresan durante el crecimiento en ejercicios numerosos que dependen de la conformación anatómica de los órganos. El gatito, al jugar solo sabrá adoptar actitudes de caza o persecución, que será la actividad más útil del adulto; pero que esta potencialmente preparada en su organismo, desde que nace.

En el niño, con la aparición de la inteligencia, viene a unirse con la raíz biológica de donde precede el juego, otros factores intelectuales, el principal de los cuales, es la imitación. De ahí que el juego puro, de raigambre biológica exclusiva, espontáneo, lo encontremos en las épocas primeras de la vida, puramente animales y en que sus manifestaciones lúdicas están alejadas de la influencia ajena. Entonces el niño no intenta imitar. El juego descansa en esta primera edad en estructuras orgánicas sencillas y no se exterioriza sino que en ejercicios como de botar, romper objetos, producir ruidos, fijarse en cuanto su mirada distingue, etc.

La antigua pedagogía atribuía al instinto de curiosidad el afán inmoderado del niño en los primeros meses de romper cuanto tiene en su mano o de cogerlo todo. Pero esto no puede ser efecto de una causa de orden intelectual tan elevado como es la curiosidad. Esto es obra de la vitalidad propia del organismo, de su actividad neuro-muscular incipiente, no regulada ni coordinada aún. Los estímulos que provocan en sus centros nerviosos las excitaciones exteriores, son devueltas en forma de contracción muscular aún no coordinada ni con objeto preciso. Es comparable este acto del lactante, con cualquier reflejo; como la salivación frente al alimento, que no significa curiosidad por conocer la estructura de él. El niño pequeño cuando rompe una cosa, no aspira a conocer el contenido de ella.

La actividad lúdica del niño durante los primeros meses, como decíamos, es tan reducida, como la significación que tiene para el mundo que lo rodea. Esta relacionada íntimamente con su organización neuro-muscular en formación. Son los juegos aquí, formas de expresión del desarrollo esquelético, muscular y nervioso. Están representados por movimientos en profusión; los órganos de la palabra, incapaces aun de expresar el pensamiento se manifiestan por gritos; el oído se complace en ruidos; los ojos, en seguir con la vista un punto luminoso o que se mueve, etc. Pero cuando el niño adquiere el dominio de sus miembros, de los órganos de los sentidos: cuando la palabra traduce ideas, el mundo infantil se enriquece sobremanera y con ello las posibilidades de juegos. Con el dominio del lenguaje y del movimiento, el niño sale de si mismo para penetrar en el mundo de sus semejantes, y comienzan los juegos a teñirse de las nuevas influencias que sobre el actúan. Viene la imitación a intercalarse en su propia personalidad espiritual. Pero hay que tener presente que siempre, el fondo biológico será la materia originaria del juego. Con imitación o sin ella, el niño jugara y convertirá en materia de juego todo lo que se le presente. Si el mundo en que vive es tan pobre que nada lo incite a la imitación, el inventara sus juegos. Una pelusa, una piedrecita, como vemos en nuestras salas, la 
tomara en sus manos, la dará vuelta, la lanzara, etc, con el mismo entusiasmo que tratará de tomarse el agua que pongan a su alcance, o con que trepara sobre el primer obstáculo que se le interponga. Pero este niño, colocado en el mundo de los demás, de los adultos, copiará sus actividades. Manejara un trompo, una pelota, una muñeca. (Hemos visto niñitas mayores de 2 años que al mostrarles una muñeca por primera vez, se han asustado).

De ahí la gran importancia que hay que dar al medio que rodea al niño, porque, según la imitación encauzara sus propias actividades. En el juego del fútbol, por ejemplo, hay un elemento primario, natural, biológico, cual es la necesidad que el niño siente de hacer fuertes contracciones musculares, impulsado por su trofismo orgánico. Se sabe que las mayores demandas de actividad en la infancia proceden del esqueleto, en particular de los huesos largos, y músculos que en ellos se insertan. Y son precisamente juegos favoritos los que hacen actuar estas partes (carrera, salto, etc). El fútbol logra esta finalidad no como conjunto de reglas establecidas para los adultos, sino porque se dirige hacia esa actividad muscular y ósea.

Respecto al juego de muñecas u otros juegos femeninos, en que obra en gran parte la imitación, también están subordinados al desarrollo orgánico, puesto que es la niñita pequeña la que gusta de este juego, en cambio, mayorcita, ya no jugará a las muñecas. Preferirá pasear, andar, saltar. Si el sexo influyera, la cosa sería al revés.

La influencia sexual, por lo demás, no se puede negar; pero es clara únicamente cuando estos órganos llegan a la madurez. Antes de esta época hoy se acepta que las glándulas sexuales, ya influencian los actos de los niños (Freud J.). Aquí es nuevamente un substrato anatómico, una glándula endocrina la que imprimirá carácter al juego. Pero la niña adquirirá aptitudes maternales, desarrollará su instinto, sin necesidad de las muñecas; igual que el niño no llegará a ser un hombre porque juega a la pelota. En el peor de los casos, será un futbolista.

En una palabra, el hombre llega a ser tal, no cuando su aprendizaje haya terminado, sino cuando los órganos han adquirido la aptitud para cumplir sus funciones propias.

\section{Comentario}

Jugar es parte fundamental del desarrollo humano, la alegría de vivir y el aprendizaje continuo. Jugar -así como crear y usar juguetes-requiere imaginación, conocimientos, habilidades y muchas otras capacidades.

Los juguetes potencian y desarrollan la fantasía, la creatividad, la exploración y el descubrimiento, la imaginación, la abstracción y el planeamiento. Además, desencadenan aprendizajes en el área cognitiva, las destrezas, actitudes y afectos y, muy en especial, en adquirir y aplicar valores. Sin duda, son fundamentales en la adquisición de competencias. Son, a la vez, básicos para desarrollar y aprender roles; en especial, los de género. Entre otras características -que, de paso, les agregan valor en el psico y en el neuro diagnóstico- se incluyen ser elementos socializadores, vehículos de expresión de sueños y frustraciones y herramientas indispensables para el desarrollo psicomotor fino y grueso. Por si todo ello fuera poco, sin duda favorecen la interacción del niño con sus padres y sus pares.

La gran cantidad de roles que se les adscribe hace pensar que es necesario que un niño tenga varios juguetes. Sin embargo, también se puede pensar que un número excesivo de ellos pudiese - por su abundancia-disminuir su valor en el concepto infantil.

Muchos tipos de juguetes fomentan más la competencia que la cooperación y el individualismo, más que el altruismo y la integración. Estos dos últimos, deseables en el fomento del desarrollo infantil, pueden ser sobrepasados por la realidad, en la que no es infrecuente que el estímulo se centre en la competencia y el individualismo.

Zorrilla hace un contrapunto entre diversas teorías sobre el juego y entre la actividad lúdica de los adultos y los niños; así como la de ambos sexos y la de especies diversas. En el texto incluye párrafos curiosos, vitales y atractivos, pese a ser eruditos: "Marañón dice que el timo es una glándula de infancia; la hipófisis de juventud; los genitales, de madurez y el tiroides, de toda la vida”. Frase para endocrinólogos, escrita hace ya muchas décadas. 